\title{
ADMINISTRATIVE SERVICES IN MUNICIPALITIES - CURRENT STATUS AND PERSPECTIVES
}

\author{
K. Kirilova* \\ University of National and World Economy, Sofia, Bulgaria
}

\begin{abstract}
Purpose. One of the major challenges facing local administration is the extension of the electronic services provided. This requires reengineering of existing processes as well as applying methodologies and technological tools to develop e-Government. The main objective of the present study is based on a survey to reveal the problems and opportunities for the municipalities to expand the process electronization and the development of the provided services. Methods. To achieve this goal, different methods are used, such as the basic method of an empirical survey among a sample of municipalities. Results. The results obtained are in the direction of studying the characteristics of the ongoing municipal processes and the search for opportunities for their electronization. Conclusions. The analytical part of the study is directed towards the formulation of basic conclusions and the search for development opportunities.
\end{abstract}

Key words: processes, reengineering, e-government, local administration, e-services

\section{INTRODUCTION}

The present study is devoted to the problems of e-services in municipalities. The general concept is related to the study of the state of the administrative processes and their management. A sampling was carried out among municipalities in the Republic of Bulgaria, on this basis a survey was conducted. The results obtained are summarized and analyzed. Part of the tools used is related to the development of own evaluation methodology, which compares the municipalities in the sample. The overall rating index that is generated gives an overview of the state and trends of the individual local administrations. Results and summaries can provide a basis for further research in this direction.

\section{METHODOLOGY OF THE SURVEY}

Local government surveys are a commonly used approach to problem area detection and decision-making. In recent years, a number of researches in this area has been focused on IT, Internet search, and human resource management in the administration. In their study Kirilov points out the importance of

\footnotetext{
*Correspondence to: Katia Kirilova, University of National and World Economy, Sofia 1700, tel. +359 28195 693, e-mail: katia.kirilova@unwe.bg
}

building the e-commune [1]. The principles that are set to electronize major administrative processes can increase the efficiency of local administration. A key place in this process is the provision of various administrative services and public electronic services. In order to allow for the development of complex administrative services [2], an important prerequisite is investment in human capital and risk management. Regarding the risk management in administrative activity and in the management of public projects, it is necessary to implement specialized software [3]. These are web-based systems that have a specific architecture and a specially designed database [4]. For these reasons, this study aims to establish the level of modeling and analysis of the working processes; the frequency of process analysis; the use of software for analysis; improvements in administrative processes; the use of systems of key management indicators; the new administrative services developed and others. In this connection a questionnaire of 12 questions has been developed. It is shaped as an on-line survey and is distributed to the municipalities in the sample (Figure 1). 


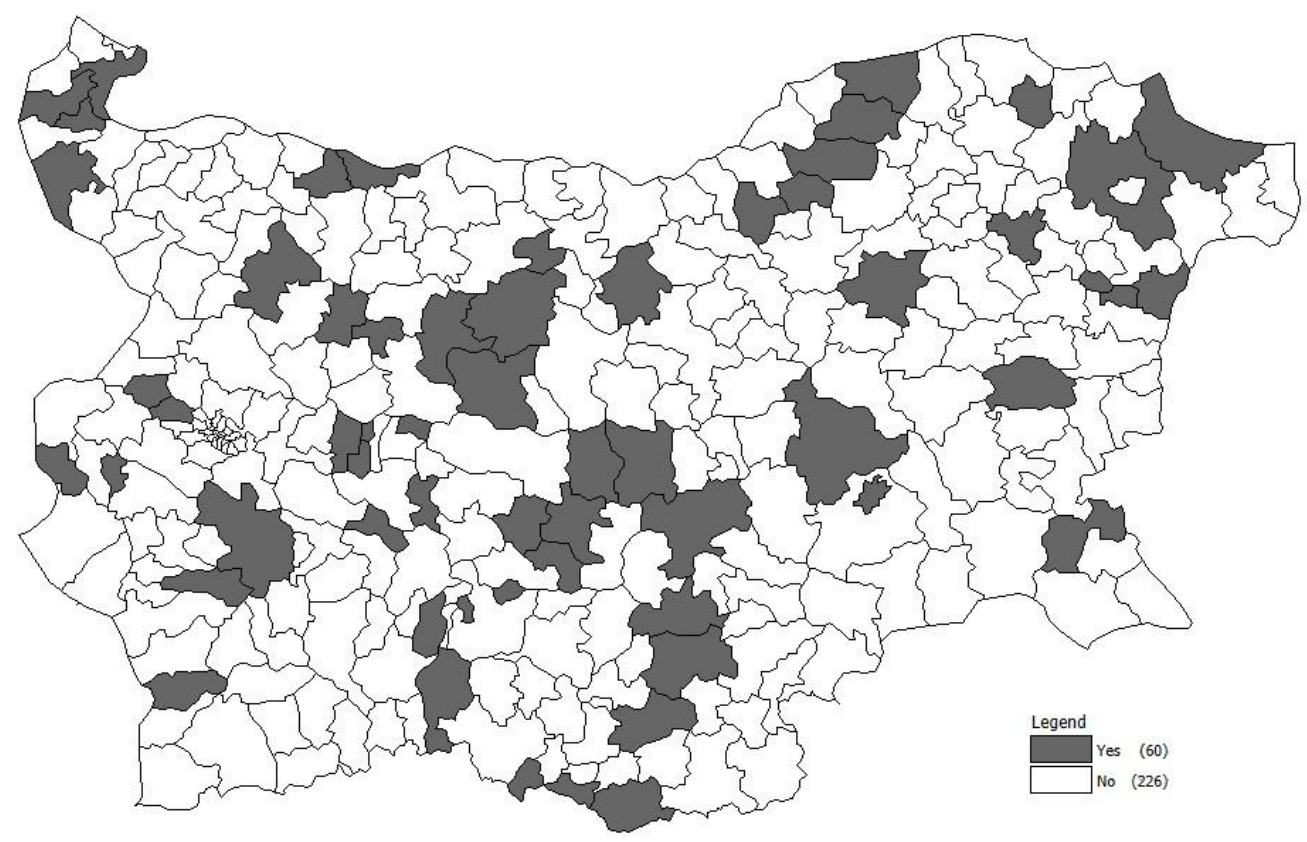

Figure 1. Municipalities in the sample

The questions included in the questionnaire are:

- Do you have your own methodology for modeling and analysis of workflows? If this question is answered in the affirmative, 100 points are placed, and in the case of negative 0 points;

- How often do you analyze work processes in your municipality? Every month - 100 points; Six months - 66 points; Once a year - 33 points; Once every few years - 0 points;

- Do you use a software product for modeling and process analysis? If this question is answered in the affirmative, 100 points are placed, and in the case of negative - 0 points;

- In connection with the improvement of the work processes, how do you analyze the needs of the administration? When this is done through one of the possible answers to the questionnaire, 100 points are placed, and when no such analysis is made - 0 points;

- Do you have an integrated system of key indicators? When the answer received is positive, 100 points are scored, 0 points negative and 50 points in the course of the response.

- How often does the administration gather and analyze information on the time and cost of providing administrative services? When doing so, 100 points are placed, 50 points occur when certain situations occur, and when no such information is collected or analyzed - 0 points. Including this issue is a serious challenge to the study. It directs to the search for opportunities through information from the Internet and users of administrative services to determine the frequency of analysis. In interpreting the data obtained on this subject, the results of some recent research in this area should be applied. Such is, for example, Milev, who focuses on the possibilities of indexing and analyzing internet publications [5];

- For what part of the administrative services are designated officials responsible for the overall implementation of the process (process owners)? When such employees are responsible for all services, 100 points are placed when such employees are responsible for more than half of the services - 66 points; when such employees are responsible for less than half of the services - 33 points; and when no such services exist - 0 points;

- How many processes are optimized in 2017? In response from 1 to 5 processes 33 points. With a response of 6 to 10 processes - 66 points. In response to more than 10 processes - 100 points. In the absence of optimized processes - 0 points;

- How many administrative services in your municipality have been updated as a result of optimizing workflows? With a response of 1 to 5 services - 33 points. With a response of 6 to 10 services - 66 points. In response to over 10 services - 100 points. When no such services are updated - 0 points; 
- How many new administrative services are created as a result of optimizing the work processes in your municipality? With a response of 1 to 5 services - 33 points. With a response of 6 to 10 services - 66 points. In response to over 10 services - 100 points. When no new services are created - 0 points;

- How many employees from the municipal administration participate in the description and modeling and the working processes? With a response of 1 to 5 employees - 33 points. With a response of 6 to 10 employees - 100 points. With a response of

\section{KIRILOVA $K$.}

over 10 employees - 66 points. When no employees are involved - 0 points;

- Is the training of municipal employees necessary after the reengineering of the working processes? If this question is answered in the affirmative, 100 points are placed and 0 points negative.

The developed questionnaire is modeled in the form of an on-line survey and is disseminated to the respondents. They include both regional centers - 12 (Figure 2) and non-district centers - 47 (Figure 3).

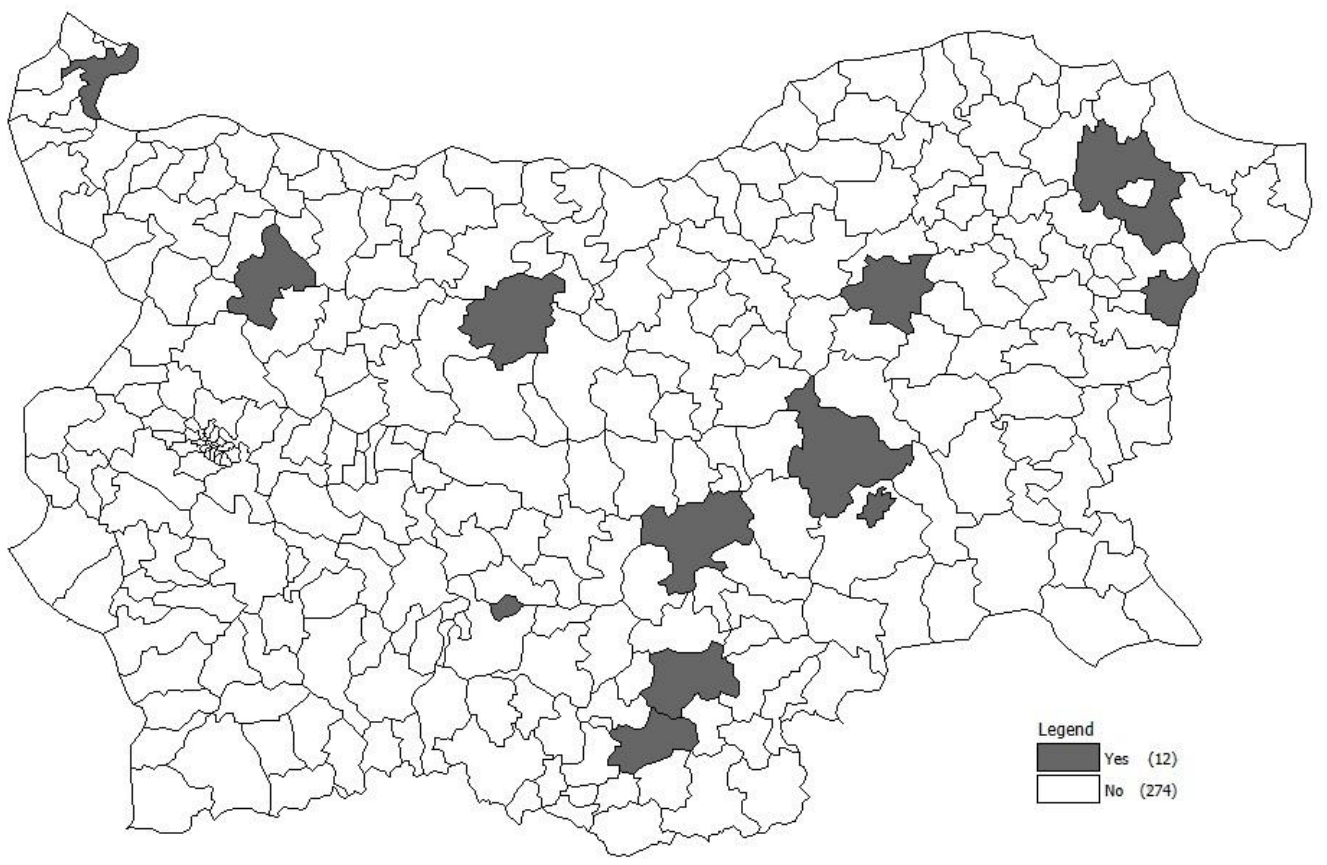

Figure 2. Municipalities in the sample, which are regional centers

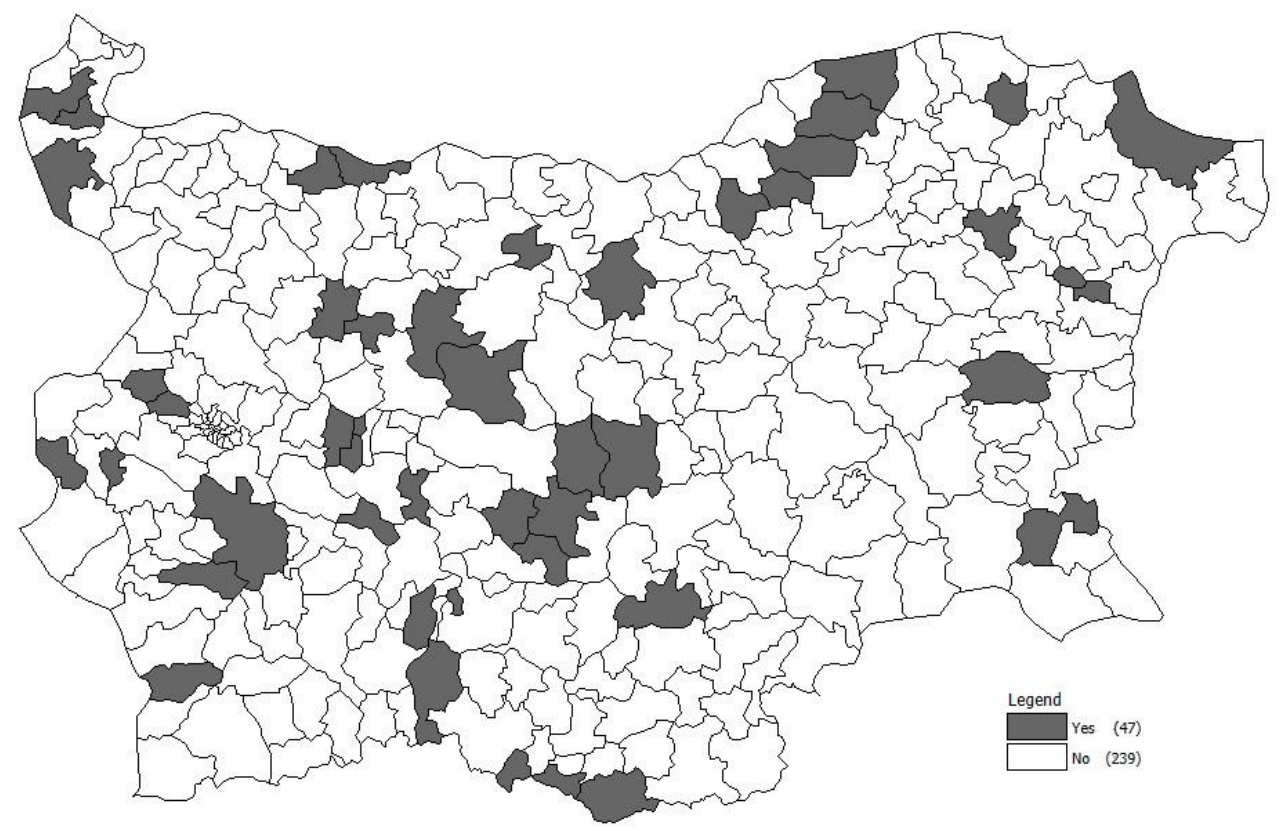

Figure 3. Municipalities in the sample, which are not regional centers 
After receiving the corresponding responses, the data will be cleared from errors, coded and recalculated as points. On this basis, some of the main results of the empirical study are presented in the next part.

\section{RESULTS OF THE EMPIRE STUDY}

After receiving the responses to the poll, they are summarized. Replies are replaced with their point equivalent. The values for all questions are averaged and the value of a common index for each municipality is obtained. It has a cognitive meaning, as it allows a comparison of the individual units of the sample. The values obtained are given in Table 1.

Table 1. Total index values

\begin{tabular}{|l|l|}
\hline Municipality & Index \\
\hline Alfatar & 29,17 \\
\hline Anton & 51,33 \\
\hline Belogradchik & 34,67 \\
\hline Beloslav & 29,08 \\
\hline Bozhurishte & 2,75 \\
\hline Bratisgovo & 62,42 \\
\hline Brezovo & 9,67 \\
\hline Chavdar & 29,17 \\
\hline Chelopech & 45,67 \\
\hline Devin & 42,92 \\
\hline Devnya & 31,75 \\
\hline Dimitrovgrad & 49,92 \\
\hline Dobrich & 54,00 \\
\hline Dve Mogili & 45,75 \\
\hline General Toshevo & 29,08 \\
\hline Gramada & 29,08 \\
\hline Haskovo & 42,92 \\
\hline Kaloyanovo & 34,58 \\
\hline Kardzhali & 49,83 \\
\hline Kazanlak & 38,75 \\
\hline Kirkovo & 55,42 \\
\hline Kovachevtsi & 67,83 \\
\hline Kresna & 54,08 \\
\hline Kubrat & 41,50 \\
\hline Kula & 77,58 \\
\hline Lesichevo & 42,83 \\
\hline Lovech & 77,58 \\
\hline Mirkovo & 59,58 \\
\hline Miziya & 59,58 \\
\hline Novi Pazar & 48,42 \\
\hline
\end{tabular}

\begin{tabular}{|l|l|}
\hline Oryahovo & 62,33 \\
\hline Ougarchin & 74,92 \\
\hline Pavel Banya & 58,17 \\
\hline Pavlikeni & 55,50 \\
\hline Perushtitsa & 34,67 \\
\hline Plovdiv & 73,50 \\
\hline Pordim & 45,75 \\
\hline Rakovski & 42,92 \\
\hline Rila & 38,83 \\
\hline Roman & 52,58 \\
\hline Rudozem & 58,25 \\
\hline Ruen & 80,42 \\
\hline Samokov & 70,75 \\
\hline Sliven & 55,33 \\
\hline Slivnitsa & 55,42 \\
\hline Sozopol & 59,67 \\
\hline Stara Zagora & 77,67 \\
\hline Strelcha & 44,33 \\
\hline Targovishte & 43,00 \\
\hline Treklyano & 41,58 \\
\hline Troyan & 66,50 \\
\hline Tsar Kaloyan & 65,25 \\
\hline Tutrakan & 48,50 \\
\hline Varna & 73,42 \\
\hline Vetovo & 11,08 \\
\hline Vidin & 67,92 \\
\hline Vratsa & 67,92 \\
\hline Yablanitsa & 29,08 \\
\hline Yambol & 49,92 \\
\hline Zlatograd & 60,92 \\
\hline & \\
\hline
\end{tabular}

The highest values of the general index (over 70 points) were obtained with the municipalities of Varna, Plovdiv, Stara Zagora, Lovech, Samokov, Ougarchin, Kula and Ruen. The lowest total index scores (less than 30 points) were obtained from Bozhurishte, Brezovo, Vetovo, Beloslav, General Toshevo, Gramada, Yablanitsa, Alfatar and Chavdar. The difference between the lowest and the highest value is 77.67 points. This means a great diversity, due to specific features that all municipalities have. The graphical representation of the results is given in Figure 4.

Figure 5 also gives a distribution of the values obtained by the municipalities in the sample. 


\section{Total Index}

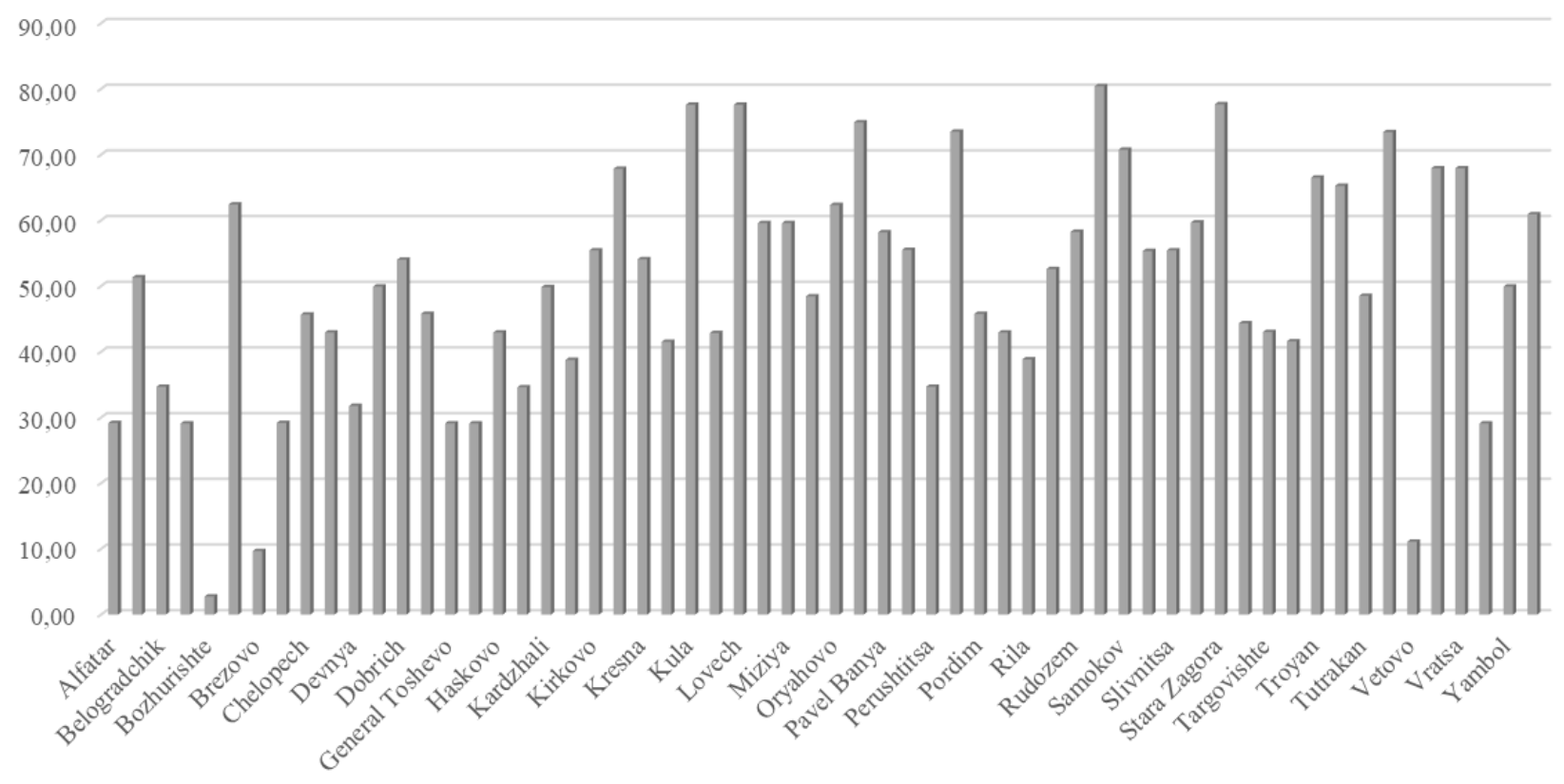

Figure 4. Distribution of the overall index

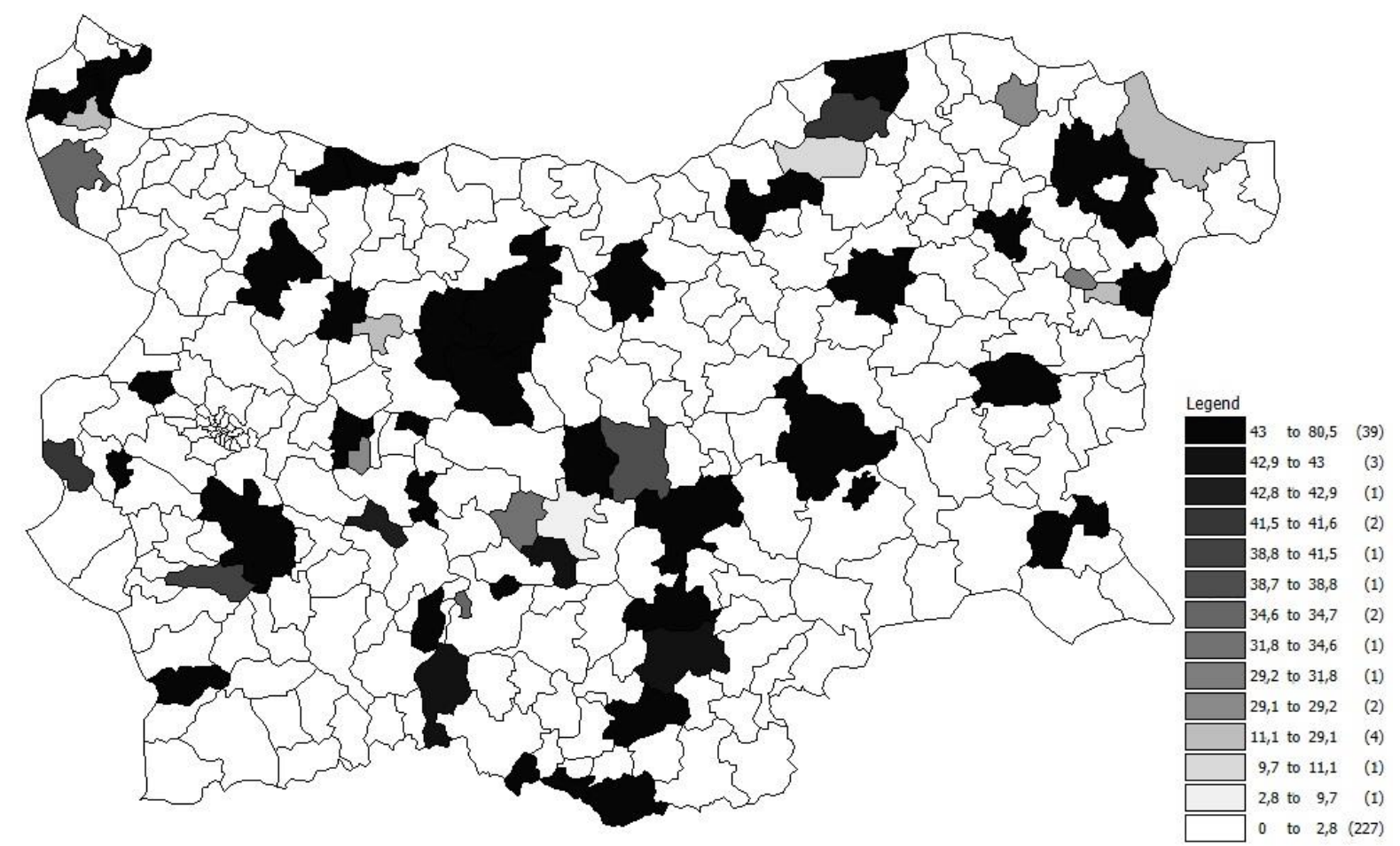

Figure 5. General index by municipalities

The survey data obtained allow the analysis of each of the questionnaires in order to reveal challenges and good practices.

\section{CONCLUSIONS}

In conclusion, the following main results can be drawn:

- Studies on the state and trends in the development of administrative services in the municipalities will continue. They represent a constant research interest in terms of digitization processes;

- In recent years, the municipalities of the Republic of Bulgaria have made considerable efforts to increase the efficiency of the local administration and the electronization of the provided administrative services;

- Small municipalities also see several good practices that can be used as a basis for 
KIRILOVA $K$.

work and example. Many good practices are observed and can serve as an example in small municipalities.

\section{REFERENCES}

1. Kirilov, R., Building E-Municipality, Problems, Approaches and Solutions, Trakia Journal of Sciences, Vol. 11, Suppl. 1, pp 58-63, 2013, Trakia University, ISSN 1313-3551 (online).

2. Daskalova, T., The human resources in the administration of "one-stop-shop", The Human Resources in the Panorama of Labor: a magazine for labor and social relations, Issue 2, 2009, pp. 26-35, ISSN 1312-305X.
3. Kirilov, R., Features of Application of Software Solutions in Public Projects Risk Management, Economic and Social Alternatives, Issue 2, 2017, pp. 127 - 140, ISSN 1314-6556.

4. Milev, P., Technological Issues of Storing Dynamic Data in a Relational Database on Research Projects, Trakia Journal of Sciences, Vol. 13, Suppl. 1, pp 22-25, 2015, ISSN 1313-7069 (print), 1313-3551 (online).

5. Milev, P., An Assessment of Information Systems for the Indexation and Analysis of Online Publications, Business Management, Issue 1, pp 55-73, 2017, ISSN 0861-6604 (print), 2534-8396 (online). 